\title{
Gas Adsorption and Sensing Mechanism Studies by Measu ring Enthalpy of Porous Materials with QCM
}

\author{
Jiaqiang Xu*, Zhiheng Ma, Zhixuan Cheng, Qun Xiang, Xiaohong Wang \\ NEST Lab, Department of chemistry, College of Science, Shanghai University, Shanghai, 200444, \\ China. \\ *E-mail: xujiaqiang@shu.edu.cn
}

\begin{abstract}
:
Quartz crystal microbalance (QCM) loaded with different porous materials was used as a new tool to measure adsorption isotherms for calculating adsorption enthalpy. The QCM devices enable to measure the adsorption isotherms and monitor the dynamic process for the adsorption of $\mathrm{CO}_{2}$ on $\mathrm{ZIF}$ 8.,UIO-66 and SBA-15- $\mathrm{NH}_{2}$ which represent three different adsorption mechanism. The adsorption isotherms of the $\mathrm{CO}_{2}$ on $\mathrm{ZIF}-8$ followed the Kraussius-Clapelon equation with the characteristic energy of $15.6 \mathrm{~kJ} \mathrm{~mol}^{-1}$. This adsorption enthalpy approximates the result of BET test $\left(14.6 \sim 14.9 \mathrm{~kJ} . \mathrm{mol}^{-1}\right)$ and the Gaussian calculation software(14.8kJ), and according with previous studies about 15 20kJ.mol-1 (belong to physical absorption). The adsorption enthalpy of $\mathrm{CO}_{2}$ on $\mathrm{UIO}-66$ was $38 \sim 42 \mathrm{~kJ}^{-\mathrm{mol}^{-1}}$, conforming with previous studies about 40kJ.mol-1 (belong to weak chemical absorption). The SBA-15$\mathrm{NH}_{2}$ was choose as a strong chemical adsorption on $\mathrm{CO}_{2}$ to explore the accuracy of this method. Fortunately, the figure obtained is in keeping with the theoretical value (greater than $80 \mathrm{~kJ} \mathrm{~mol}^{-1}$ ) . As a result, the above three adsorption enthalpy measured by QCM are consistent with that calculated from the earlier adsorption theory. This will open a new route to judge if the material is suitable for adsorptive and sensing materials.
\end{abstract}

Key words: QCM, adsorption, adsorption enthalpy, ZIF-8, $\mathrm{CO}_{2}$

\section{Results and Discussion}

QCM transducer was employed to measure enthalpy of three different adsorption that physical adsorption, chemical adsorption and weak chemical adsorption.

Fig. 1 shows the $\mathrm{CO}_{2}$ adsorption isotherms on $\mathrm{ZIF}-8$ at $273 \mathrm{~K}$ and $287 \mathrm{~K}$ in the pressure range from 0 to 35 bar. It can be seen that the $\mathrm{CO}_{2}$ uptake increased drastically with pressure. Which can be attributed to the micropore adsorption.

Fig.2 shows the adsorption enthalpy $(\Delta \mathrm{H})$ of $\mathrm{CO}_{2}$ on ZIF-8 determined by measuring two isotherms at $287 \mathrm{~K}$ and $273 \mathrm{~K}$, and fitting the data to the virial model. The enthalpy of adsorption enthalpy $(\Delta \mathrm{H})$ for ZIF-8 is 14.7 $\mathrm{kJ} / \mathrm{mol}$ approximately .

Fig. 3 and Fig. 4 were two stable configuretions for the complex $\mathrm{C}_{4} \mathrm{H}_{6} \mathrm{~N}_{2} \quad \cdots \mathrm{CO}_{2}$ to analog computation. The most stable conformation has the $\mathrm{CO}_{2}$ on the imidazole ring top position (Fig.3), with $\mathrm{C}\left(\mathrm{CO}_{2}\right)$ at a distance of 3.556 and $3.958 \AA$ from two imidazole ring $\mathrm{N}$ atoms and $4.494 \AA$ from the methyl $C$ atom. The stability of the conformation is caused by the quadrupole- $\pi$ electron interaction between the $\pi$ electrons on the imidazole ring and the electron-deficient carbon of the $\mathrm{CO}_{2}$ molecule, as well as by the weak interaction between the methyl and $\mathrm{CO}_{2}$ molecule. And less stable configuration has the $\mathrm{CO}_{2}$ positioned beside the methyl group with the shortest distance $\mathrm{O}$ $\left(\mathrm{CO}_{2}\right) \cdots \mathrm{H}$ (methyl) of $3.239 \AA$ (Fig.4) because there is a hydrogen bond-like interaction between $\mathrm{O} \quad\left(\mathrm{CO}_{2}\right)$ and $\mathrm{H}$ (methyl). The simulated

Fig.5 and Fig.6 were the responses of ZIF-8 based QCM towards $\mathrm{CO}_{2}$ in two different temperature of $273 \mathrm{~K}$ and $287 \mathrm{~K}$. It is obvious that temperature cause low responses the frequency shift represent adsorbing capacity.

Fig.7 was a fitting model from Fig.5 and Fig.6. According to the Kraussius-Clapelon equation, choose any same adsorption capacity point can calculate different enthalpy of adsorption $(\Delta \mathrm{H})$ about $15.6 \mathrm{~kJ} / \mathrm{mol}$. 


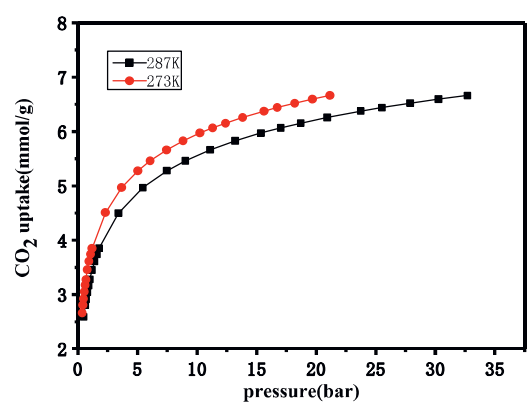

Fig. $1 \mathrm{CO}_{2}$ adsorption-desorption isotherm on ZIF-8 at $287 K$ and $273 K$

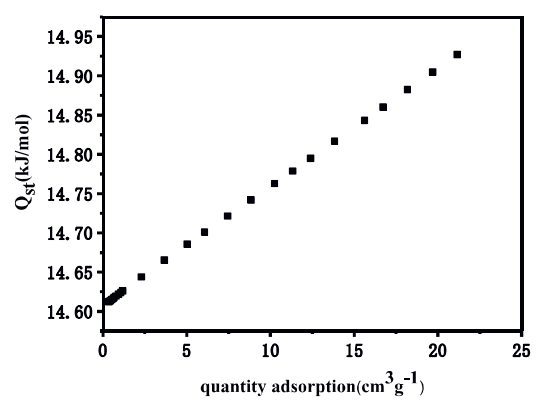

Fig. 2 Dependence of enthalpy of adsorption on the a mounts adsorbed of $\mathrm{CO}_{2}$ over ZIF-8

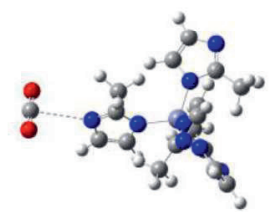

Fig.3 DFT-optimized stable configurations of the com plex $\mathrm{C}_{4} \mathrm{H}_{6} \mathrm{~N}_{2} \cdots \mathrm{CO}_{2}$ in ZIF-8 of $\mathrm{C} \cdots \mathrm{N}$

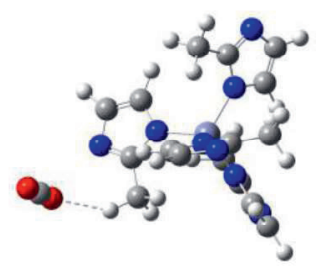

Fig.4 DFT-optimized stable configurations of the com plex $\mathrm{C}_{4} \mathrm{H}_{6} \mathrm{~N}_{2} \cdots \mathrm{CO}_{2}$ in ZIF-8 of $\mathrm{O} \cdots \mathrm{H}$

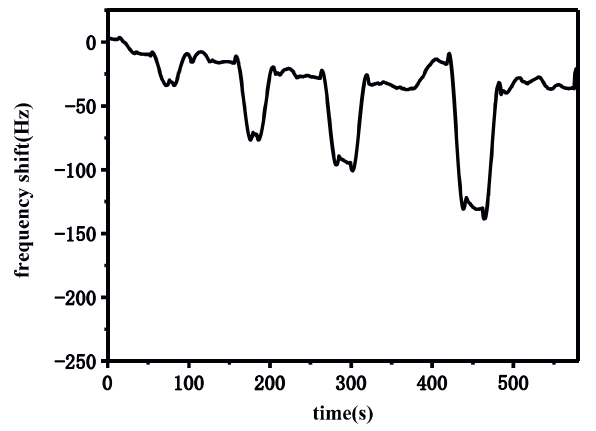

Fig. 5 response curve of different concentrations of $C$ $\mathrm{O}_{2}$ at $287 \mathrm{~K}$

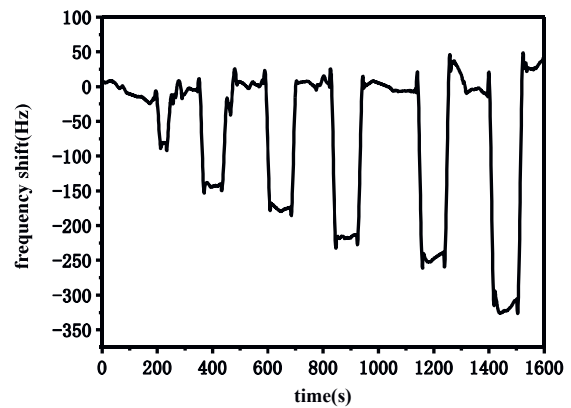

Fig. 6 response curve of different concentrations of $C$ $\mathrm{O}_{2}$ at $273 \mathrm{~K}$

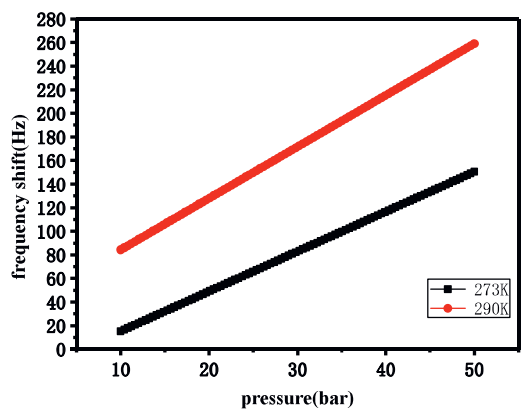

Fig. $7 \mathrm{CO}_{2}$ adsorption isotherm on ZIF-8 at $287 \mathrm{~K}$ and 273K fitting from QCM

\section{Reference}

[1] Liu, Defei, et al. "Experimental and molecula $r$ simulation studies of $\mathrm{CO}_{2}$, adsorption on $\mathrm{z}$ eolitic imidazolate frameworks: ZIF-8 and a mine-modified ZIF-8." Adsorption-journal of the International Adsorption Society19.1(20 13):25-37. DOI 10.1007/s10450-012-940 $7-1$

[2] Xu, Fen, et al. "A pyridine vapor sensor bas ed on metal-organic framework-modified qu artz crystal microbalance." Sensors \& Actua tors B Chemical 254(2017):872-877.DOI: 1 0.1016/j.snb.2017.07.026 